\title{
Characteristics of Infant Child Care: Factors Contributing to Positive Caregiving
}

\author{
NICHD Early Child Care Research Network
}

\begin{abstract}
At 6 months of age, 576 infants were observed during 2 half-days in five types of nonmaternal child care (centers, child care homes, in-home sitters, grandparents, and fathers). Settings were assessed in terms of their structural characteristics (group size, child-adult ratio, physical environment) and caregivers' characteristics (formal education, specialized training, child care experience, and beliefs about child rearing). In addition, caregivers' interactions with infants were observed. Caregivers were rated as providing more positive caregiving when group sizes and child-adult ratios were smaller and when caregivers held less-authoritarian beliefs about child rearing. Significant differences were associated with type of care arrangement. Child-adult ratios and group sizes were largest in centers and smallest in informal in-home care (with fathers, grandparents, and in-home sitters); specialized training was highest in centers. Small group sizes, low childadult ratios, caregivers' nonauthoritarian child-rearing beliefs, and safe, clean, and stimulating physical environments were consistently associated with positive caregiving behaviors within each of these different types of settings.
\end{abstract}

The study is directed by a Steering Committee and supported by NICHD through a cooperative agreement (U10) that calls for a scientific collaboration between the grantees and the NICHD staff. The participating investigators are listed in alphabetical order with their institutional affiliations designated by number: Mark Appelbaum (14); Dee Ann Batten (14); Jay Belsky (2); Cathryn Booth (12); Robert Bradley (4); Celia Brownell (9); Bettye Caldwell (4); Susan Campbell (9); Alison Clarke-Stewart (5); Jeffrey Cohn (9); Martha Cox (8); Kaye Fendt (1); Sarah Friedman (1); Kathryn Hirsh-Pasek (3); Aletha Huston (6); Nancy Marshall (15); Kathleen McCartney (7); Marion $O^{\prime}$ Brien (6); Margaret Tresch Owen (10); Deborah Phillips (11); Henry Ricciuti (1); Susan Spieker (12); Deborah Lowe Vandell (13); and Marsha Weinraub (3). The institutional affiliations, in alphabetical order, are the National Institute of Child Health and Human Development (1); Pennsylvania State University (2); Temple University (3); University of Arkansas (4); University of California-Irvine (5); University of Kansas (6); University of New Hampshire (7); University of North Carolina-Chapel Hill (8); University of Pittsburgh (9); University of Texas-Dallas (10); University of Virginia (11); University of Washington (12); University of Wisconsin-Madison (13); Vanderbilt University (14); and Wellesley College (15). We are grateful to the hard-working site coordinators and research assistants and to the families and child-care providers who tolerated our presence with good grace and cooperated with our repeated requests for information.

Correspondence and requests for reprints should be sent to Deborah Lowe Vandell, University of Wisconsin, Wisconsin Center for Educational Research, 1025 West Johnson Street, Madison, WI 53706. 
In response to what they identified as "a quiet crisis" confronting infants and their families, the Carnegie Corporation (1994) called for strong and immediate changes to improve the quality of nonparental infant care in the United States. In particular, they called for efforts to adopt, support, and monitor nationwide child care standards for children under 3 years of age. But what should these standards be, and what impact will they have on the emotional and intellectual well-being of children?

Unfortunately, there has been little research that can answer these questions with regard to infants. Most existing child care research has not included infants or has combined infant and toddler care in ways that cannot be disentangled. Thus, there is an assumption, essentially untested, that high-quality care for infants can be defined in the same terms as care for older children, that is, by child-adult ratios, group sizes, and caregivers' qualifications. For example, a joint statement issued by the American Public Health Association and the American Academy of Pediatrics (1992) advocated that group sizes should not exceed six children and that child-adult ratios should be no larger than 3:1 for children under 2 years of age. Experts rating child care across the country for Working Mother magazine (Cadden, 1994) also focused on structural characteristics (group sizes not exceeding six to eight infants and ratios not higher than $4: 1$ ). But do these dimensions influence the kinds of caregiving experiences that infants have, and do these experiences ultimately contribute to children's development?

In this investigation, observations from the National Institute of Child Health and Human Development (NICHD) Study of Early Child Care are used to examine associations between structural and caregiver characteristics as they apply to infants' experiences with their caregivers. Subscquent articles will examine the effects of these infant child care experiences on children's social and intellectual development. Data for the NICHD study were collected at 10 research sites located across major regions of the United States and including urban, suburban, and rural settings. Infants were enrolled in the study at birth and included those from families who did not anticipate using child care during the infant's 1 st year as well as those who planned to use care on a full-time or part-time basis. This recruitment plan reduced the possibility that care arrangements would be limited to those that were regulated and publicly accessible or to those that parents were pleased with before they volunteered for the study. At 6 months, infants who were in a nonmaternal care arrangement for 10 or more hr per week were observed in that arrangement. Covering the gamut of contemporary child care, these nonmaternal care arrangements included care by fathers, grandparents, and in-home sitters as well as in centers and child care homes.

To evaluate these different arrangements, an observational instrument, the Observational Record of the Caregiving Environment (ORCE), was developed to record caregivers' behaviors, identified in the research literature as 
contributing to children's social and intellectual development, such as responding promptly to the infant's social signals and distress, expressing positive feelings toward the infant, and stimulating the infant's cognitive development. These caregivers' behaviors are examined in relation to the child care standards suggested by the experts-child-adult ratios, group sizes, and caregivers' formal education and specialized training. Other possible standards such as caregivers' experience and beliefs about child rearing and the safety of the physical environment also are examined.

\section{STRUCTURAL AND CAREGIVER CHARACTERISTICS ASSOCIATED WITH OBSERVED CAREGIVING BEHAVIORS}

Many researchers and professionals consider a low child-adult ratio the sine qua non of high-quality child care. Nevertheless, studies of child-adult ratios in classrooms for preschool-age children have not always shown strong relations with observational measures of caregiving (Clarke-Stewart, Gruber, \& Fitzgerald, 1994; Dunn, 1993; Phillips, Scarr \& McCartney, 1987; Ruopp, Travers, Glantz, \& Coelen, 1979). Investigations of toddler classrooms have been more consistent in revealing positive effects of low child-adult ratios. In one study of 12- to 18-month-olds attending child care centers. Allhusen (1992) found that caregivers provided more positive and individualized care when child-adult ratios were smaller ( $3: 1$ vs. $4: 1$ and $4: 1$ vs. 6:1). The Infant/Toddler Day Care Study, a substudy of the National Day Care Study (Ruopp et al., 1979), also revealed that caregivers spent less time managing children in classrooms with lower child-adult ratios and that children appeared less apathetic and less distressed. In the Child Care Staffing Study (Whitebook, Howes, \& Phillips, 1990), child-adult ratio was the best predictor of teachers' developmentally appropriate activities and sensitivity with toddlers. In our study, we hypothesize that child-adult ratio will be particularly important because the developmental needs of infants often require individual attention.

We also hypothesize that caregivers' behaviors will be related to the number of children in the infant's group or class. This structural measure has been related to observed caregiving in several studies of toddler classrooms in child care centers. For example, both Allhusen (1992) and Ruopp et al. (1979) found that group size was predictive of cargivers' behaviors, even after the contribution of ratio was statistically controlled. Similarly, Howes (1983) observed that caregivers with fewer toddlers in their child care classrooms were more responsive, more socially stimulating, and less restrictive than caregivers who were responsible for more children. However, in other center-based investigations (Burchinal, Roberts, Nabors, \& Bryant, 1996; Scarr, Eisenberg, \& Deater-Deckard, 1994; Whitebook et al., 1990), 
ratio alone, not group size, was the important variable in predicting caregivers' behaviors.

In child care homes, where ratio and group size are often the same because there is only one caregiver, the significance of having more children in the care arrangement is consistently apparent. Nearly all researchers studying home-based care have documented the effects of larger numbers of children on providers' behavior. With a larger group of young children to care for, caregivers appear less sensitive, less responsive, less positive, and less sociable; they engage in one-to-one interaction with children less often, and their interactions are more likely to involve attempts to control and restrict the children's activities (Fosburg, 1981; Howes, 1983; Stallings, 1980; Stith \& Davis, 1984). Even with only one other child present, each child receives less attention from the caregiver, and with more children present, each child receives less positive caregiving (affection, responsiveness, and stimulation) (Clarke-Stewart et al., 1994). In the Chicago Study of Child Care and Development (Clarke-Stewart et al., 1994) and in the National Day Care Home Study (Fosburg, 1981), group size was the strongest predictor of homebased caregivers' behavior. Only Galinsky, Howes, Kontos, and Shinn (1994) reported that home caregivers provided "higher quality" care when they cared for more children-three to six children rather than one or two.

In the NICHD study, we expect that sensitive, warm, and responsive caregiving will be compromised by large group sizes in both centers and homes and that both ratio and group size will influence caregiving.

A third feature suggested as a child care standard is the educational background of the caregiver. Although an association has not been reported in every study (e.g., Clarke-Stewart et al., 1994; Dunn, 1993), caregivers' formal education and specialized training have been linked to caregivers' behavior in many toddler and preschool programs (Arnett, 1989; Berk, 1985; Ruopp et al., 1979). Berk (1985), for example, observed that center caregivers who had gone to college and had some training in child development were less likely to restrict children's activities, more likely to encourage them, more likely to use indirect forms of guidance, and more likely to make efforts to develop the children's verbal skills. Logue, Eheart, and Steinkamp (1989) observed that preschool teachers with degrees in early childhood education were more likely to emphasize academic skills than were those without degrees.

In infant care, however, we submit that the issue is not the caregiver's emphasis on academics or her style of discipline, but the sensitivity and affective quality of her caregiving. Support for the importance of caregiver's sensitivity and warmth comes mostly from studies of parent-infant relationships. Crockenberg and Covey (1991), for example, reviewed a number of studies and concluded that insensitive, rejecting, and hostile parental behavior with young children is associated with children's later externalizing behaviors. Cox, Owen, and Lewis (1989) reported that parental 
warmth and positive regard during the 1st year are related to children's cooperativeness and positivity at age $21 / 2$ years. Early parental detachment has been related to children's subsequent display of weaker task orientation (Easterbrooks \& Goldberg, 1984). Early parental stimulation has been related to children's preschool intelligence scores (Bradley \& Caldwell, 1976). Research is needed to investigate how these aspects of caregiving behavior are related to caregivers' background and children's behavior in child care settings.

One aspect of caregivers' backgrounds that may be relevant to providing sensitive and warm care is experience with young children. In some inquiries (Dunn, 1993; Howes, 1983; Kontos \& Fiene, 1987), researchers have observed warmer and more responsive caregiving when caregivers are more experienced. Other research, however, has not replicated these results (Kontos, 1994; Whitebook et al. 1990). In still other investigations, caregivers' experience has been associated with more detached and harsh care (Galinsky et al., 1994) and less stimulation and interaction (Kagan \& Newton, 1989; Ruopp et al., 1979). Apparently the link between caregiving behaviors and caregivers' experience is not a simple one. Using the NICHD study, we examine relations between caregivers' experience and other factors that may explain these discrepancies.

Finally, at least in parents' and caregivers' minds, the physical environment is an important part of child care. Researchers have studied this dimension infrequently, but their results do suggest that more stimulating care occurs in centers and child care homes with better organized space and more varied materials (Dunn, 1993; Howes, 1983; Scarr et al., 1994). The NICHD study included evaluations of the physical environments in child care settings that could potentially confirm these findings.

In summary, one of our goals is to identify the structural characteristics and caregivers' qualifications that are associated with caregiving behaviors that are sensitive, warm, and responsive to infants. We hypothesize that caregivers' training and education are positively related to the quality of their interactions with the study infants and that having fewer children to care for in a safe and physically stimulating environment allows caregivers to provide the most attentive and positive care. We do not make a prediction about how caregivers' experience is related to these interactions.

\section{CHARACTERISTICS \\ OF DIFFERENT TYPES OF CHILD CARE}

Our second goal is to examine variations in structural and caregivers' characteristics as a function of the type of care. Previous studies have compared two types of care settings: home based (typically child care homes) and center based. At least for toddlers and preschoolers, these two kinds of 
settings differ in their structural characteristics. On average, homes have smaller group sizes and smaller child-adult ratios; center caregivers have higher levels of education and training (Clarke-Stewart et al., 1994; Golden et al., 1978; Howes, 1983; Kisker, Hofferth, Phillips \& Farquhar, 1991); centers offer more stimulating physical environments (toys and play materials) (Clarke-Stewart et al., 1994; Golden et al., 1978). Differences also are apparent in children's experiences in the two settings. Centers generally offer more educational and informative experiences (Clarke-Stewart et al., 1994; Goelman, 1988; Kisker et al., 1991), whereas homes generally of fer more one-to-one interaction with the caregiver (Clarke-Stewart et al., 1994).

The NICHD study extends the comparison of child care settings beyond these two types of care to include care by fathers, grandparents, and inhome sitters. This broad, inclusionary strategy was followed so that we might investigate the full range of nonmaternal child care arrangements experienced by infants. Fathers were included because very little information is available about this form of care, even though almost $20 \%$ of the families with infants use fathers as their primary child care arrangement (Hofferth, Brayfield, Deich, \& Holcomb, 1991). Similarly, little research is available regarding care by in-home sitters and grandparents, although these are often preferred forms of care for infants (Scarr, 1984). It is expected that these informal care arrangements will have lower group sizes and child-adult ratios and lower levels of caregivers' training than child care centers and child care homes.

Caregivers' behaviors are expected to vary in these different types of care. Previous research with older children revealed that more stimulating experiences are found in centers (Clarke-Stewart et al., 1994) and in formal child care homes (Galinsky et al., 1994) than in informal in-home care. This research would lead to the prediction that centers and child care homes would provide more stimulating care than fathers, grandparents, or in-home sitters. However, the intensity of infants' needs may be more difficult to meet when group sizes and ratios are larger or when caregivers are unrelated to the child and, therefore, less emotionally involved. If this is the case, fathers, grandparents, and in-home sitters might provide more sensitive, responsive, and positive care for infants. Information from the NICHD study affords the opportunity to test these rival predictions.

\section{DESCRIPTION OF INFANT CARE}

Our third purpose is to provide descriptive data about nonmaternal infant care in the United States. Several recent reports have suggested that child care for many children in the United States is inadequate. For example, in the Cost, Quality, and Child Outcomes Study (Helburn et al., 1995), researchers evaluated the adequacy of the physical settings and the presence of activities to 
promote children's language, reasoning, learning, and social development in $\mathbf{4 0 0}$ randomly sampled child care centers in four states (California, Colorado, Connecticut, and North Carolina). They concluded that most [of the observed] child care is mediocre in quality, sufficiently poor in quality to interfere with children's emotional and intellectual development. In that study, infant-toddler classrooms were particularly problematic $(40 \%$ were rated as being of less than minimal quality, $52 \%$ were rated as mediocre, $8 \%$ as good). In the Child Care Staffing Study (Whitebook et al., 1990), toddler classrooms in 227 day care centers in three states (California, Virginia, and Georgia) were evaluated; $25 \%$ of these classrooms were judged to offer less than minimal quality care. A report by Galinsky et al. (1994) of home-based child care arrangements in three states (California, Texas, and North Carolina) described $35 \%$ as inadequate; only $9 \%$ were rated as good. These figures may in fact inflate the actual quality of care existing in the United States, because of high refusal rates $(45 \%)$ by center directors and home care providers. It seems likely that programs and providers who refuse to be observed may provide poorer quality care than those who agree to participate (Whitebook et al., 1990).

These previous reports of poor or minimally adequate child care for toddlers underscore the need for a large-scale investigation to answer the following questions: What are the structural characteristics of infant child care settings? What are the characteristics and qualifications of infant caregivers? Are caregivers' behaviors related to these structural characteristics and caregiver qualifications? Do caregivers' behaviors vary in different types of settings? Because of the developmental needs and vulnerabilities of infants it is particularly urgent that we address these issues.

\section{METHOD}

\section{Participants}

Participants in the NICHD Study of Early Child Care were recruited throughout 1991 from 31 hospitals at the 10 research sites: (1) Little Rock, Arkansas; (2) Orange County, California; (3) Lawrence and Topeka, Kansas; (4) Boston, Massachusetts; (5) Philadelphia, Pennsylvania; (6) Pittsburgh, Pennsylvania; (7) Charlottesville, Virginia; (8) Morganton and Hickory, North Carolina; (9) Seattle, Washington; and (10) Madison, Wisconsin. These 10 sites had been selected as a result of the peer review of grant proposals submitted to NICHD in response to the institute's request for applications to participate in a collaborative network studying the effects of early child care experiences.

Hospital visits were made to all mothers who had given birth during selected 24-hr sampling periods. A total of 8,986 mothers were visited. From these visits, 5,416 families were determined eligible to participate in the 
study (mother speaks English, mother over 18 years of age, baby healthy, and no plans to move from the area in the coming year). The network's centralized data coordinating center then generated telephone call lists for each site using a conditional random sampling plan designed to ensure that sampled families reflected the demographic characteristics of the catchment area. From these lists, 1,364 families were recruited for the study (approximately 136 families per site). Recruited families closely approximated the demographic characteristics of the "population" defined as the 5,416 eligible families. For additional details of the recruitment plan see NICHD Early Child Care Research Network (1995) and the NICHD Study of Early Child Care manual (1992).

\section{Data Collection and Creation of Variables}

Visits to the families began when the infants were 1 month old. At 5 months, mothers were telephoned and asked about their current child care arrangements and if changes were anticipated in the next month. If no changes were anticipated, information about the child care setting was obtained. If mothers anticipated changes, they were called back 1 month later to find out about the infants' current child care arrangement. Five types of nonmaternal care were identified: father care, grandparent care, in-home sitter (in the child's home), child care home (care provided in the caregiver's home, $27 \%$ were licensed), and child care center.

At 6 months of age, 879 infants were in a nonmaternal care arrangement. Of these infants, 198 were in more than one care arrangement. For children in more than one arrangement, a primary arrangement was identified. A primary arrangement was operationally defined as the one in which the infant spent the most time or, if the child spent equal time in two arrangements, the more "formal" or institutional arrangement. For all children in a single arrangement for 10 or more hours per week, providers $(N=734)$ were contacted and asked to participate in the study.

Observations were not conducted for 113 infants who qualified for observation but whose providers refused to be observed. Eleven (or $11 \%$ ) of the eligible fathers contacted, 15 (or 13\%) of eligible grandmothers, 11 (or $11 \%$ ) of eligible in-home sitters, 73 (or $27 \%$ ) of the eligible child care home providers, and 3 (or $3 \%$ ) of the eligible centers refused observation. An additional 24 children were not observed because the visits could not be scheduled within the assessment window. A total of 597 infants were visited and observed in their primary nonmaternal child care arrangement; of these 576 could be classified as being in one of our five types of care. These child care observations were evenly distibuted across the 10 research sites.

Table 1 gives demographic characteristics of the total study sample as well as of families who used any nonmaternal child care each week. For a detailed examination of family factors (demographic and psychological) 
Table 1. Characteristics of the NICHD Sample Familes $(N=1,364)$

\begin{tabular}{|c|c|c|c|c|}
\hline & $\begin{array}{c}\text { Total } \\
\text { Sample } \\
(n=1364) \\
n(\%) \\
\end{array}$ & $\begin{array}{c}\text { Families With } \\
\text { Any Child Care } \\
\begin{array}{c}\text { at } 6 \text { Months } \\
(n=879) \\
n(\%)\end{array} \\
\end{array}$ & $\begin{array}{c}\text { Familes Whose } \\
\text { Child Care } \\
\text { Was Observed } \\
\begin{array}{c}(n=576) \\
n(\%)\end{array} \\
\end{array}$ & $\begin{array}{c}\text { Families With } \\
\text { Eligible Child } \\
\text { Care That } \\
\text { Was Not } \\
\text { Observed } \\
(n=156) \\
n(\%) \\
\end{array}$ \\
\hline \multicolumn{5}{|c|}{ Educational Level of Mother } \\
\hline$<12$ grade & $139(10)$ & $55(6)$ & $25(4)$ & $18(12)$ \\
\hline High school or GED & $287(21)$ & $163(19)$ & $107(19)$ & $37(24)$ \\
\hline Some college & $455(33)$ & $306(35)$ & $196(34)$ & $59(38)$ \\
\hline BA level work & $284(21)$ & $191(22)$ & $134(23)$ & $24(15)$ \\
\hline Postgraduate work & $198(15)$ & $163(19)$ & $114(20)$ & $18(11)$ \\
\hline \multicolumn{5}{|c|}{ Education of Father or Partner } \\
\hline$<12$ grade & $105(8)$ & $52(6)$ & $31(6)$ & $16(12)$ \\
\hline High school or GED & $284(23)$ & $178(22)$ & $111(21)$ & $38(28)$ \\
\hline Some college & $371(30)$ & $242(30)$ & $168(32)$ & $42(31)$ \\
\hline BA level work & $271(22)$ & $175(22)$ & $123(23)$ & $20(15)$ \\
\hline Postgraduate work & $219(17)$ & $171(20)$ & $101(6)$ & $18(13)$ \\
\hline \multicolumn{5}{|l|}{ Child's Race } \\
\hline White & $1042(76)$ & $684(78)$ & $455(79)$ & $110(71)$ \\
\hline Black & $173(13)$ & $98(11)$ & $58(10)$ & $27(17)$ \\
\hline Asian & $19(1)$ & $14(2)$ & $9(2)$ & $3(2)$ \\
\hline Hispanic & $83(6)$ & $53(6)$ & $35(6)$ & $10(6)$ \\
\hline Native American & $2(.1)$ & $1(.1)$ & $1(.2)$ & $0(0)$ \\
\hline Other & $45(3)$ & $28(3)$ & $18(3)$ & $6(4)$ \\
\hline \multicolumn{5}{|l|}{ Partner at Home } \\
\hline Yes & $1166(86)$ & $756(86)$ & $508(88)$ & $121(78)$ \\
\hline No & $198(14)$ & $123(14)$ & $68(12)$ & $35(22)$ \\
\hline \multicolumn{5}{|l|}{ Income-to-Needs Ratio } \\
\hline $0-1.0$ & $310(24)$ & $169(21)$ & $101(19)$ & $34(25)$ \\
\hline $1.0-1.8$ & $194(15)$ & $130(16)$ & 83 (15) & $32(23)$ \\
\hline $1.8-2.0$ & $80(6)$ & $51(6)$ & $37(7)$ & $10(7)$ \\
\hline $2-3$ & $268(21)$ & $179(22)$ & $126(23)$ & $25(18)$ \\
\hline $3-4$ & $158(12)$ & $103(13)$ & $74(14)$ & $13(9)$ \\
\hline$>4$ & $264(21)$ & $187(23)$ & $117(22)$ & $25(18)$ \\
\hline
\end{tabular}

a Child care observations were only conducted in primary arrangements that were attended for at least $10 \mathrm{hr} /$ week.

${ }^{b}$ Families with eligible child care that was not observed included refusals $(n=113)$ and visits that could not be scheduled.

associated with child care usage, the reader is referred to the article by the NICHD Early Child Care Research Network (1996) on this issue.

Table 1 also gives the characteristics of families whose child care was eligible for observation at 6 months (i.e., the child was in the setting for at least $10 \mathrm{hr} /$ week) broken down into those families whose child care was 
actually observed and those families for whom we were unable to observe their eligible child care because of refusals or scheduling problems. There are some differences in those families in which eligible child care was observed and those families in which eligible care was not observed. Mothers' and fathers' educations were higher in those families whose eligible child care was observed, $t(241)=4.26, p<.001$, and $t(199)=3.37, p<.001$, respectively. Income-to-needs ratios also were higher for those families whose eligible child care was observed, $t(212)=2.56, p<.01$. Children from single-parent households and those with minority race status were more likely to be in eligible, but nonobserved child care, $\chi^{2}(1)=11.47, p<.001$, and $\chi^{2}(1)=5.01, p<.03$, respectively.

Two half-day visits to observe and assess the infants' child care experiences were scheduled to occur within a period of 2 weeks. The first of these visits was within 2 weeks of the infant's 6-month birthday, and at this visit observers typically completed two ORCE observation cycles and the appropriate Assessment Profile scale. At the second visit, two additional ORCE observations were made, and the Child Care HOME (Caldwell \& Bradley, 1984) evaluation was completed for home-based care. Interviews were held with caregivers and questionnaires were administered to them at the end of the visit. This data collection plan served two methodological purposes: it provided the assurrance that data were not collected on a single, possibly atypical, occasion, and it permitted observers to be blind to caregivers' views and background while observing their behavior.

Observational Assessments. A major innovation in this study was the development of an observational instrument, the ORCE, to assess the characteristics of caregiving for an individual child. This instrument is particularly valuable because it can be used to assess children's experiences in different types of settings. Other measures are applicable only for centerbased care or only for home-based care. Also, in contrast to other instruments, such as Harms and Clifford's (1980) Early Childhood Environment Rating Scale (ECERS), the Observational Record of the Caregiving Environment (ORCE) focuses on caregivers' behaviors with a specific child (in this case, the study child) rather than on what happens in the classroom at large. This innovation was especially appropriate for the NICHD study because we intend to examine how these individual child experiences contribute to children's subsequent development. A third feature of the ORCE is that it provides both frequency counts (called behavior scales) and ratings (called qualitative ratings) of caregivers' behaviors. The behavior scales provide a record of the occurrence (or quantity) of specific acts, whereas the qualitative scales takes into account quality (and nuances) of the caregiver's behaviors in relation to the child's behaviors. Specific items that constitute the ORCE behavior scales and qualitative ratings are listed in Table 2. These 
categories and ratings were developed following an extensive review that identified these domains as being important to infant development.

The ORCE format consists of 44-min cycles, each broken into four 10min observation periods. In each 10 -min period observers alternate between 30-s observe and record frames. During the observe intervals observers focus on the study child's behavior, activities, and interaction with the caregiver or other people. During the record intervals the observer completes the frequency checklist. At the end of the 10-min period the observer makes brief notes and tentative qualitative ratings of behaviors for $2 \mathrm{~min}$. This process is repeated for three 10-min periods. In the final 10-min period the observer makes observations exclusively for the qualitative ratings. At the end of the $\mathbf{4 4}$ min the observer makes final qualitative ratings using 4-point scales that range from not at all characteristic to highly characteristic based on all four 10-min periods. Typically four 44-min ORCE cycles, distributed over 2 days, were completed for each infant. For the 576 children in this report, the average number of complete 44 -min cycles was 3.9. Training and reliability procedures for the ORCE are detailed later in the Method section.

Although most infants (79\%) were observed with the same caregiver across the four observation cycles, some were observed with two $(11 \%)$, three $(7 \%)$, or more $(3 \%)$ caregivers. Our qualitative ratings are based on the caregiver for whom we had the most complete data. The behavior scales included frequencies of acts for all available caregivers.

For purposes of this article, a composite variable based on the ORCE behavior scales called positive caregiving frequencies was created by averaging three standardized behavioral summary scores that included nine of the original behavior categories: positive behavior (shared positive affect + positive physical contact), responsive behavior (responds to vocalization + facilitates infant behavior), and stimulating behavior (stimulates cognitive development + stimulates social development + asks question + other talk + reads); Cronbach's alpha $=.81$. This a priori combination, which the investigators believed best reflected positive caregiving for infants, was supported by a confirmatory factor analysis of the behavior scale observations in which the first factor (accounting for $49 \%$ of the variance, factor loadings between .49 and .81 ) was identical to this composite variable, except that it did not include positive physical contact.

A composite variable based on the ORCE qualitative ratings was constructed by summing five of the qualitative ratings: sensitivity or responsiveness to nondistressed communication, positive regard, stimulation of cognitive development, detachment (reflected), and flat affect (reflected). This composite was labeled positive caregiving ratings. Scores varied from 5 to $20(M=14.8, S D=3.0$; Cronbach's alpha $=.89)$. The first principal component of a confirmatory factor analysis (accounting for $70 \%$ of the variance) corresponded to this a priori conceptually constructed composite 


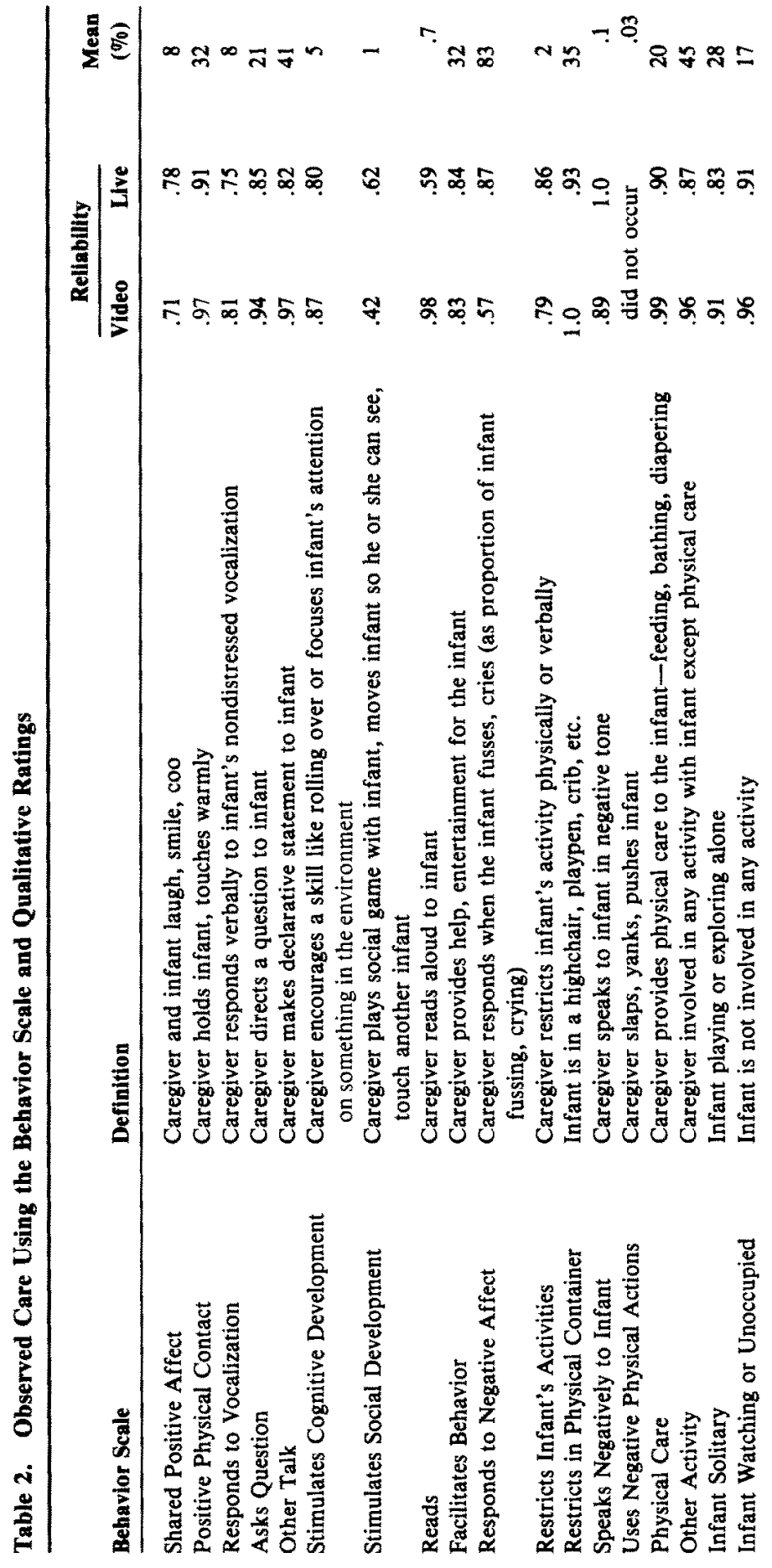




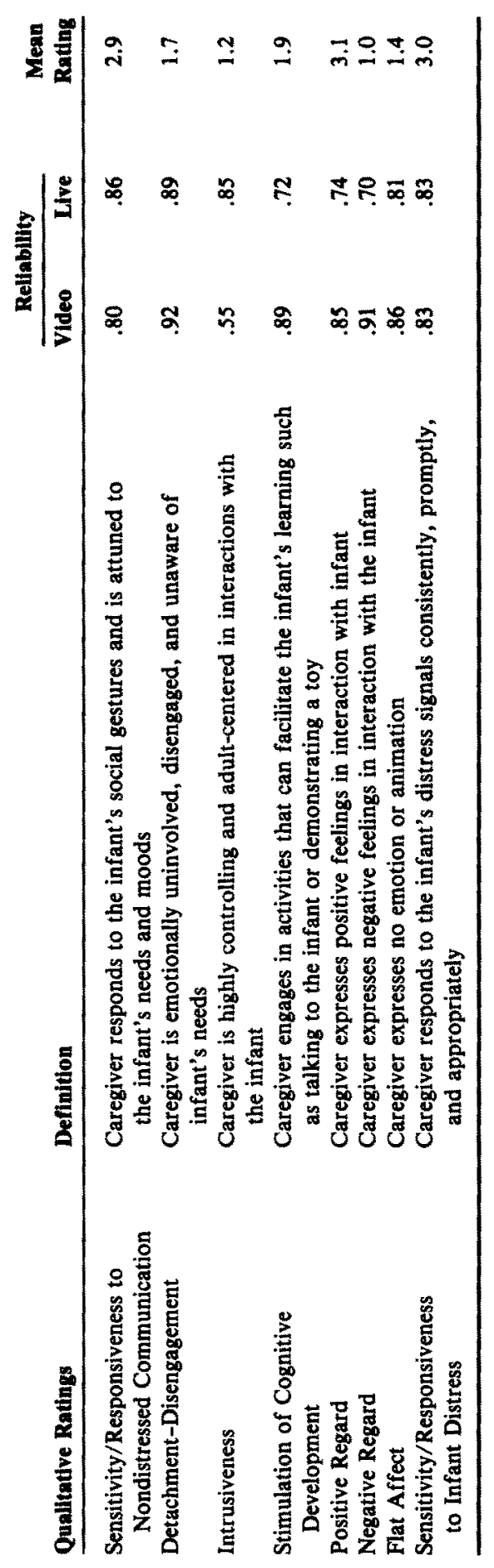


variable (factor loadings .65-.91). The qualitative composite did not include the ratings of intrusiveness or negative regard because extensive pilot observations indicated little variability in these rarely observed domains.

At the beginning and end of each ORCE cycle observers recorded the composition of the group of adults and children in the care setting. Variables derived from these records included: group size, representing the average across ORCE cycles of the number of children under 13 years observed in infant's group; child-adult ratio, representing the average across the ORCE cycles of the number of awake children observed per caregiver; and age mix of children $(1=$ study child alone, $2=$ infants only, $3=$ infants and toddlers only, $4=$ children beyond age 2 present, in at least $75 \%$ of the observed cycles).

In addition to the ORCE assessments, two other observational instruments were used. Caldwell and Bradley's (1984) HOME inventory (with the wording of some items modified by Caldwell and Bradley to make them more appropriate for child care situations) was completed in all home-care arrangements. The Child Care HOME employs an interview and observation format to assess caregivers' responsivity, acceptance, and involvement with the child, the organization and learning materials in the home environment, and the variety of experiences offered the child. The 45 items, scored yes or no, had a Cronbach's alpha of .81 .

The other observation instrument was the Assessment Profile for Early Childhood Programs (Abbott-Shim \& Sibley, 1987). This instrument provided a classroom-level assessment and was available in two versions, for centers and for homes. Three additional items from Wachs (1991) were added to assess quiet, crowding, and clutter. For the purposes of this investigation, a subset of items was selected from this instrument to provide a measure of the physical environment of the child care setting. These items evaluated the extent to which the space and equipment wcre clean and safe, the environment was uncrowded and uncluttered, a variety of developmentally appropriate toys was available, and the infant had a play area that was protected and quiet (17 items in the center scale, Cronbach's alpha $=.64$, and 29 items in the home scale, Cronbach's alpha $=.74)$.'

Caregiver Interviews and Questionnaires. Structured interviews with the caregivers administered at the end of the second child care visit formed the basis for the following variables: caregiver's formal education (scored as

The somewhat low alpha coefficients for the Assessment Profile were not viewed as problematic for two reasons. First, the Profile was used in the current study as a predictor, not an effect indicator. According to Bollen (1989), high values of alphas are neither required nor expected for predictor indicators. Second, in the case of the Profile, a large number of items, each with a low prior probability of occurrence (e.g., exposed electrical outlets) were scored. There was no reason, empirically or theoretically, to expect strong intercorrelations among the items. Rather, these items can be seen as a sample of "unsafe" or "unstimulating" conditions. 
$1=$ less than high school graduation, $2=$ high school diploma or GED, $3=$ some college, $4=$ bachelor's degree, $5=$ some graduate work, including master's degree, $6=E d D, P h D$, or other post-master's degree); specialized training in child development or early education (scored as $0=$ none, $1=$ high school courses, $2=$ adult or vocational courses, $3=$ college courses, $4=$ college or graduate degree); caregiving experience (years of providing child care or working in a child care or early childhood center); caregiver's own child(ren) present during the time that the study infant is in care $(0=$ absent $; 1=$ present $)$.

Caregivers' beliefs about child rearing were assessed using a 30-item questionnaire that discriminates between "modern" and "traditional" child-rearing beliefs (Schaefer \& Edgerton, 1985). A principal component factor analysis yielded a single dimension of nonauthoritarian child-rearing beliefs. Cronbach's alpha for the 30-item scale was .90. The caregiver with nonauthoritarian beliefs believes that children are basically good, learn actively, and should be allowed to disagree with their parents if they feel their own ideas are better, rather than believing that it is more important to teach children to value obedience and authority.

\section{Training and Reliability}

The 24 child care observers first studied the extensive manuals prepared by the investigators, which detailed each assessment procedure, and then they were trained in all observation and interview procedures at a 1-week group session. This training consisted of viewing master-coded videotapes, conducting "live" observations in centers and home-based child care settings, completing written tests, and participating in question-and-answer sessions pertaining to each procedure. Further training and practice were conducted at each site using videotaped and live examples and instruction. Then, questions that arose in the course of collecting the observational data were answered by the instrument developers via E-mail sent to all observers.

To ensure cross-site reliability on the ORCE observations, before any data collection was initiated, observers coded six tapes, each containing one 44-min ORCE cycle. These tapes had been master coded by the investigators who developed the ORCE. The tapes represented all five types of care and captured a range of quality. To be certified as data collectors, each observer had to achieve exact agreement with the master codes of the behavior scales at a level of $70 \%$ or better and with the qualitative ratings at a level of $60 \%$ or better. After certification, reliability was checked across the 10 months of data collection with three further rounds of videotape testing, each consisting of six new master-coded 44-min ORCE cycles. To remain certified, observers had to maintain exact agreement with the master codes of the behavior scales at a level of $70 \%$ or better and with the qualitative ratings at a level of $60 \%$ or better. In fact, agreement was typically much higher. 
Two reliability estimates were computed for individual observers' scores for each specific behavior and qualitative rating using the master-coded videotapes. They were Pearson correlations and an estimate computed from the repeated measures ANOVA formulations presented in Winer (1971). Table 2 gives the median reliability across observers for each individual variable estimated using the Pearson correlations. Similar estimates were derived from the repeated measures ANOVA procedure.

In addition to using master-coded videotapes, which ensured that sites were applying similar standards to their ORCE assessments, pairs of observers at each site completed qualitative ratings and behavior checklists during visits to child care settings. These "live" observations occurred across the 10-month data collection period. At each site, all possible pairs of observers were required to visit both home-based and center-based child care. A total of 84 pairs of observers ( 168 ORCE cycles) were included in the live reliability assessments for the behavior categories and 88 pairs of observers (176 cycles) for the qualitative ratings. Pearson correlations and repeated measures ANOVAs were used to estimate reliability at the variable level. Reliability estimates based on the Pearson correlations are given in Table 2. Similar estimates were derived from the repeated measures ANOVA procedure.

Interobserver reliabilities also were determined for the composite variables derived from the qualitative ratings and the behavior categories. The median reliability (Pearson correlation) for the positive caregiving rating composite was .94 for the master-coded videotapes and .90 for the live observations. Reliability for the positive caregiving frequency composite was .98 for the videotapes and .86 for the live observations.

Training and certification on the Child Care HOME procedure was under the supervision of a different team of investigators within the research network. These investigators used a combination of videotaped and live experiences analogous to those used for the ORCE. To be certified, observers had to obtain $90 \%$ agreement (41 out of 45 items correctly scored) with a master-coded videotape of a Child Care HOME. In addition, an observer at each site was responsible for conducting a Child Care HOME interview that was videotaped and assessed by the scale developers for appropriateness of administration and accuracy of scoring $(90 \%$ agreement with the master coders). The site videotape also was scored by others at the site, with $90 \%$ agreement being required. The observer whose Child Care HOME administration was certified was then responsible for accompanying all other child care observers at the site to verify their approach to administering the Child Care HOME.

Approximately 3 and 6 months after data collection began, sites were sent two additional master-coded videotapes. Each observer independently viewed these tapes and submitted his or her score sheets to the data coordinating center. Observers had to maintain $90 \%$ agreement with the master codes to retain certification. 
Observers were trained on the home and center versions of the Assessment Profile by developers of that instrument at the group training. (These were different investigators than those responsible for the ORCE and the Child Care HOME.) The scale developers accompanied the observers on visits to both home- and center-based settings. The scale developers highlighted key aspects of the settings. They provided written responses to observers' queries throughout data collection. Observers' agreement with the scale developers and with other observers who had extensive experience with the scales were assessed during these live visits. Overall agreement across items and observers was $80 \%$.

\section{RESULTS}

Four sets of analyses are presented: (a) descriptive analyses pertaining to structural features, caregivers' characteristics, and caregivers' behaviors for care that we observed; (b) analyses showing the associations between these structural features and caregivers' characteristics and our observations of positive caregiving for the sample as a whole; (c) analyses showing the differences in structure, caregivers' characteristics, and positive caregiving associated with type of care arrangement; and (d) analyses examining the predictors of positive caregiving in different types of care.

\section{Characteristics of Observed Infant Care}

Infants' nonmaternal child care arrangements varied widely in structural and caregivers' characteristics (see Table 3). Infants were observed in groups that varied in size from a single child to 30 children; the majority were in groups of 1 to 3 children. Observed child-adult ratios varied from $<1: 1$ to $13: 1$. Roughly equal numbers of infants $(15 \%-18 \%)$ were found in four types of care (with fathers, grandparents, in-home sitters, and in centers); twice as many infants $(35 \%)$ were in child care homes. In child care centers it was most common for infants to be in classrooms with other infants only $(52 \%)$. In some home-care settings (fathers, grandparents, and in-home sitters), infants were most often cared for alone (79\%); whereas in child care homes, children were typically cared for in mixed-age groupings with older children $(78 \%)$. In child care homes, most caregivers $(65 \%)$ cared for their own children while the study infant was present.

The majority of care providers had either a high school diploma or some college education. About one third had had specialized training in child development or infant care. The largest number of caregivers had less than 1 year of experience in child care provision-implying that the study child was the first infant they had cared for.

Pearson correlations among structural and caregivers' characteristics are presented in Table 4. As expected, observed group size and child-adult ratio were strongly and positively related. In addition, providers who cared 
Table 3. Structural and Caregivers' Characteristics of Nonmaternal Caregiving for 6-Month-Old Infants

\begin{tabular}{lrr}
\hline Characteristic & $\boldsymbol{n}$ & $\%$ \\
\hline Type of ehild care arrangement & 87 & 15 \\
$\quad$ Father & 98 & 17 \\
Grandparent & 85 & 15 \\
In-home sitter & 201 & 35 \\
Child care home & 105 & 18 \\
Child care center & & \\
Observed group size $(\boldsymbol{M = 3 . 3 , S D = 3 . 2 )}$ & 219 \\
(averaged across $\mathbf{2}$ days, $\mathbf{5 s}$ rounded up) & 38 \\
1 & 168 & 29 \\
$2-3$ & 119 & 21 \\
$4-7$ & 46 & 8 \\
$8-11$ & 24 & 4
\end{tabular}

Observed child-adult ratio $(M=2.1: 1, S D=1.5)$

(averaged across 2 days, .5s rounded up)

1.1

2:1

$3: 1$

$4: 1$

$5: 1$

$\geq 6: 1$

$\begin{array}{rr}244 & 43 \\ 146 & 26 \\ 93 & 16 \\ 39 & 7 \\ 23 & 4 \\ 21 & 4 \\ & \\ 78 & 14 \\ 192 & 34 \\ 191 & 34 \\ 61 & 11 \\ 35 & 6 \\ 8 & 1\end{array}$

Caregivers' education $(M=2.7, S D=1.1)$

Less than high school (1)

High school diploma (2)

Some college (3)

College degree (4)

Some graduate (5)

Graduate degree (6) 5 15

18

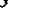

Specialized training in child development $(M=.9, S D=1.3)$

None (0)

High school level (1)

Vocational certification (2)

College level courses (3)

Degree (4)

\begin{tabular}{rr}
366 & 65 \\
24 & 4 \\
77 & 14 \\
81 & 14 \\
18 & 3 \\
& \\
379 & 71 \\
152 & 29 \\
& \\
250 & 45 \\
125 & 22 \\
76 & 14 \\
45 & 8 \\
48 & 9 \\
15 & 3 \\
\hline
\end{tabular}




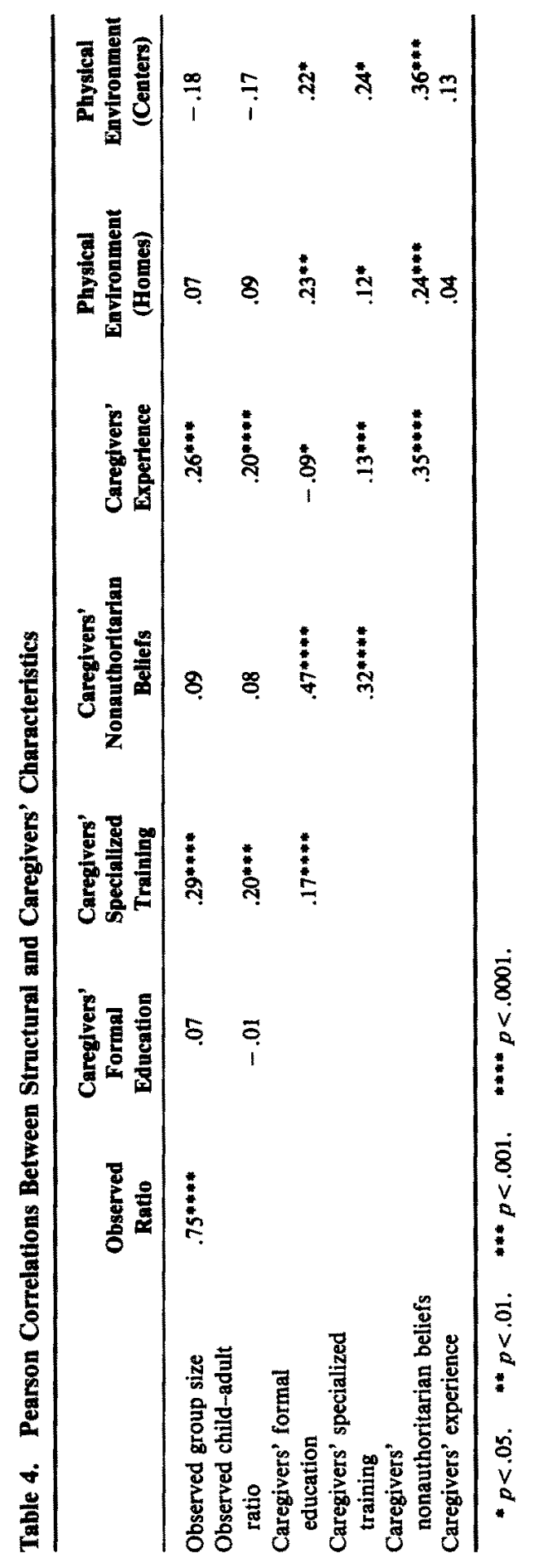


for more children had worked longer in child care and had more specialized training pertaining to children. The number of children cared for was not strongly related to caregivers' level of formal education, nonauthoritarian beliefs, or the extent to which the physical environment was highly rated.

Caregivers with more formal education had more specialized training pertaining to children, held less authoritarian child-rearing beliefs, and were in settings that were rated as more safe, clean, and stimulating. Caregivers with less authoritarian beliefs had more specialized training and experience in child care, as well as more formal education, and provided safe, clean, and stimulating physical settings.

The size of the associations between structural and caregivers' characteristics ranged from .17 to .75 ; most, although statistically significant, were relatively small (between .20 and .40 ).

Table 5 shows the means and distributions of the observers' ratings of caregivers, averaged across the four 44-min observation cycles. Most caregivers were rated as moderately or highly sensitive and moderately or highly positive to the infant. The majority of caregivers appeared either minimally or not at all detached, and explicit negative regard for the infant was rare. Cognitive stimulation was not a major aspect of caregivers' interactions with 6-month-olds: the majority of caregivers were rated as either not at all stimulating or somewhat unstimulating.

Mean percentages for the individual behavior scales across all available ORCE cycles are presented in Table 2. From these data, it is apparent that, on average, infants were involved with the caregiver in some kind of activity, beyond simple physical caretaking, for nearly half of the time they were observed. Warm, physical contact and helpful or entertaining interactions with the caregiver were observed in one third of the $30 \mathrm{~s}$ observation intervals, and caregivers responded within 30 s to over $80 \%$ of the instances of observed infant distress. Speaking negatively or using rough physical actions with the infant was almost never observed. Attempts by the caregiver to deliberately stimulate the infant's development, however, were rare (observed in only about $6 \%$ of the intervals).

The correlation between the two composite measures of caregiving, based on the qualitative ratings and the behavior scales, was $.74(p<.001)$. This correlation indicates a significant correspondence between caregiver behaviors assessed quantitatively_by summing the incidence of specific behaviors-and qualitatively - by making evaluative ratings. We retained both composites because we suspected that the amount of caregiver attention (i.e., the frequencies of caregiver behaviors) might be more affected by group size and ratio, whereas the quality of the caregivers' behaviors and responses might be more affected by child-rearing beliefs and training. Validation of the two ORCE measures (in-home settings) was provided by the Child Care HOME $(M=34, S D=5.6)$, which was significantly correlated 
Table 5. Quality of Observed Caregiving

\begin{tabular}{|c|c|c|}
\hline Characteristic & $n$ & $\%$ \\
\hline \multicolumn{3}{|c|}{ Sensitivity to nondistressed communication } \\
\hline Highly insensitive (1) & 18 & 3 \\
\hline Moderately insensitive (2) & 128 & 23 \\
\hline Moderately sensitive (3) & 282 & 50 \\
\hline Highly sensitive (4) & 133 & 24 \\
\hline \multicolumn{3}{|l|}{ Positive regard } \\
\hline Not at all positive (1) & 15 & 3 \\
\hline Minimally positive (2) & 93 & 17 \\
\hline Moderately positive (3) & 244 & 43 \\
\hline Highly positive (4) & 210 & 37 \\
\hline \multicolumn{3}{|l|}{ Detachment } \\
\hline Not at all detached (1) & 277 & 49 \\
\hline Minimally detached (2) & 179 & 32 \\
\hline Moderately detached (3) & 85 & 15 \\
\hline Highly detached (4) & 20 & 4 \\
\hline \multicolumn{3}{|l|}{ Negative regard } \\
\hline Not at all negative (1) & 544 & 97 \\
\hline Minimally negative (2) & 17 & 3 \\
\hline Moderately negative (3) & 1 & .1 \\
\hline Highly negative (4) & 0 & 0 \\
\hline \multicolumn{3}{|c|}{ Stimulation of cognitive development } \\
\hline Not at all stimulating (1) & 145 & 26 \\
\hline Minimally stimulating (2) & 273 & 49 \\
\hline Moderately stimulating (3) & 129 & 23 \\
\hline Highly stimulating (4) & 14 & 3 \\
\hline \multicolumn{3}{|l|}{ Flat Affect } \\
\hline Not at all flat (1) & 373 & 66 \\
\hline Sontewhat flat (2) & 135 & 24 \\
\hline Predominantly flat (3) & 47 & 8 \\
\hline So flat it is worrisome (4) & 8 & 1 \\
\hline
\end{tabular}

Note. These are mean ratings across 2 days of observation (four 44-min ORCE cycles), $<.5$ s rounded up.

with both positive caregiving ratings $(r=.63, p<.001)$ and positive caregiving frequencies $(r=.40, p<.001)$ composites. It should be noted that the mean Child Care HOME score was at the high end of the normal range of U.S. families (32-34) (Bradley, 1995).

Structural Characteristics and Caregiver Qualifications Associated With Caregiving Behaviors One of our major goals was to determine if structural and caregiver characteristics were associated with the quality of caregivers' interactions with the 
Table 6. Correlations Between Structural and Caregivers' Characteristics and Observed Positive Caregiving

\begin{tabular}{lcc}
\hline & \multicolumn{2}{c}{ Positive Caregiving } \\
\cline { 2 - 3 } Characteristics & Ratings & Frequencies \\
\hline Observed group size & $-.36^{* * * *}$ & $-.46^{* * * *}$ \\
Observed child-adult ratio & $-.36^{* * * *}$ & $-.45^{* * * *}$ \\
Caregivers' formal education & $.11^{* *}$ & .03 \\
Caregivers' specialized training in child development & -.02 & -.05 \\
Caregivers' nonauthoritarian child-rearing beliefs & $.14^{* *}$ & $.09^{*}$ \\
Caregivers' years of experience & -.07 & -.15 \\
Physical environment (homes) & $.33^{* * *}$ & .10 \\
Physical environment (centers) & $.47^{* * *}$ & $.31^{* *}$ \\
\hline
\end{tabular}

${ }^{*} p<.05 . \quad{ }^{* *} p<.01 . \quad{ }^{* * *} p<.001 . \quad{ }^{* * * *} p<.0001$.

study infant. We hypothesized that small group sizes and small child-staff ratios would be associated with infants receiving more positive caregiving. Caregivers' education and training also were expected to contribute positively to caregiving quality.

Correlations between the structural and caregivers' characteristics and the caregiving composites that were derived from the frequency counts and ratings are shown in Table 6 . Higher positive caregiving ratings and frequencies were observed in child care arrangements with fewer children and with lower child-adult ratios, in settings that were assessed as safer and physically more stimulating, and in programs in which caregivers had more formal education and held more nonauthoritarian beliefs about child rearing. These significant correlations were moderate in size, ranging from .31 to .47 . A statistically significant but smaller correlation $(-.15)$ was obtained between observed caregiving and caregivers' experience, indicating that positive caregiving was more frequent among caregivers with fewer years in the field. Observed caregiving was not significantly correlated with specialized training pertaining to children.

Multiple regression analyses were conducted to determine the extent to which observed caregiving was simultaneously associated with sructural and caregivers' characteristics (group size, child-adult ratio, child-rearing beliefs, experience, formal education, and specialized training). Positive caregiving frequencies (adjusted $R^{2}=.19, p<.0001$ ) and positive caregiving ratings (adjusted $R^{2}=.27, p<.0001$ ) were predicted by the full model including these six variables. Characteristics of the physical environment were not included in these regression analyses because different versions of the instrument were used in home-based settings and in centers.

A backward elimination procedure was then used to determine which variables in the full model could be removed without substantially reducing 
Table 7. Backward Elimination Regressions Predicting Observed Positive Caregiving Across Characteristics of Caregiving

\begin{tabular}{lcc}
\hline & \multicolumn{2}{c}{ Observed Positive Caregiving } \\
\cline { 2 - 3 } Predictor & Ratings & Frequencies \\
\hline & betas & betas \\
Observed group size & $-.23^{* * * *}$ & $-.28^{* * * *}$ \\
Observed child-adult ratio & $-.22^{* * *}$ & $-.28^{* * * *}$ \\
Caregivers' nonauthoritarian beliefs & $.17^{* * *}$ & $.14^{* * *}$ \\
Caregivers' years of experience & {$[3]$} & {$[3]$} \\
Caregivers' specialized training & {$[2]$} & {$[1]$} \\
Caregivers' formal education & {$[1]$} & {$[2]$} \\
Adjusted $R^{2}$ & $.19^{* * * *}$ & $.27^{* * * *}$ \\
\hline
\end{tabular}

Note. Numbers in brackets refer to order in which variables were backward eliminated. Standardized regression coefficients (betas) are provided for each significant predictor.

${ }^{*} p<.05 . \quad{ }^{* *} p<.01 . \quad{ }^{* * *} p<.001 . \quad{ }^{* * * *} p<.0001$.

predictability. ${ }^{2}$ The bracketed numbers in Table 7 indicate the order in which variables were eliminated using the backward elimination procedure. As shown in Table 7, group size, child-adult ratio, and nonauthoritarian child-rearing beliefs all accounted for significant variation in observed positive caregiving frequencies and ratings. ${ }^{3}$ Other variables included in the full model (caregivers' formal education, years of experience, and specialized training) did not significantly add to the prediction of observed positive caregiving for 6-month-olds.

\footnotetext{
${ }^{2}$ It is important to note that within the backward elimination procedure the full model is first tested for significance, that is, we achieve "alpha control" on the full model. The backwards stepdown procedure then asks, in a statistically proper method-proper from both a Type I and Type II error perspective-which variables can be eliminated from the set without substantially (i.e., significantly) reducing the predictability of the criterion. This is a particularly important issue when the predictor variables are correlated. Without having achieved the optimal set of predictor variables, the interpretation of partial beta weights can be extremely difficult, because they index the contribution of the variables given the other predictors in the system. If we allow a large set of correlated predictors, it is possible (even likely) that the contribution of potent, important, and even causal variables can be diluted by the presence of aliases or surrogate variables.

${ }^{3}$ We have chosen to present the standardized forms of these estimated weights because we feel it is easier to see what is happening when all variables are placed on the same measurement scale, same in the sense of having the same scaled variance. This same information could be presented in the unscaled form, which has the advantage of allowing the question of how much of an increase (or decrease) in the outcome can be expected from a unit change in the predictor, all other values in the model being held constant. The major disadvantage of unscaled beta estimates is that they are often misinterpreted because larger values do not necessarily signal stronger effects.
} 


\section{Comparisons of Different Types of Care}

Our second primary goal was to contrast infants' experiences in five types of arrangements. Two rival hypotheses were examined: (a) infants receive more positive caregiving in formal center-based care and (b) infants receive more positive caregiving in home-based settings. ANOVAs were used to contrast the features of the five types of care-father care, grandparent care, in-home sitter, child care home, and child care center. As shown in Table 8, significant differences were found. Tukey post hoc comparisons indicated that child-adult ratio and group size were largest in child care centers, followed by child care homes, followed by in-home care (with the father, grandparent, or sitter). Not surprisingly, specialized training in child development was highest for caregivers in centers. Fathers had more formal education than other nonmaternal caregivers, although their level of education was not higher than that of other fathers in the study (mean level of education for fathers in the sample $=3.3$; mean level of education for fathers who were care providers $=3.3$ ). Grandparents and in-home sitters had the most authoritarian child-rearing beliefs. Fathers and grandparents had the least experience providing child care, and caregivers in centers and child care homes had the most. No difference in the quality of the physical environment was found for the four home-based types of care.

As shown in Table 8, observed caregiving behaviors varied by type of care. Both composite measures of positive caregiving (ratings and frequencies) were higher for father care, grandparent care, and in-home sitter care than they were in child care homes where, in turn, they were higher than for care in centers. A significant difference also was found for the Child Care HOME scores; fathers received higher scores than other home-based caregivers.

\section{Factors Associated With Positive \\ Caregiving in Different Types of Care}

The purpose of the fourth set of analyses was to identify the factors associated with positive caregiving in different types of care. Three types of care were examined: (a) relative home care (fathers and grandparents), (b) nonrelative home care (in-home caregivers and child care homes), and (c) center care. ${ }^{4}$ Multiple regressions were conducted within these different types of care to parallel the analyses conducted for the whole sample. Predictors were, as before, child-adult ratio, group size, caregivers' formal education,

\footnotetext{
4 These three groupings of types of arrangement were used because they made sense conceptually (close relative, home-like setting, center) and because the sample sizes for in-home sitter, fathers, or grandparents were not large enough for reliable regressions. The sample size for the child care home arrangement was large enough for the number of predictors. Results of regression analyses conducted on the child care home data alone directly paralleled those reported for the combined child care home and in-home sitter data.
} 


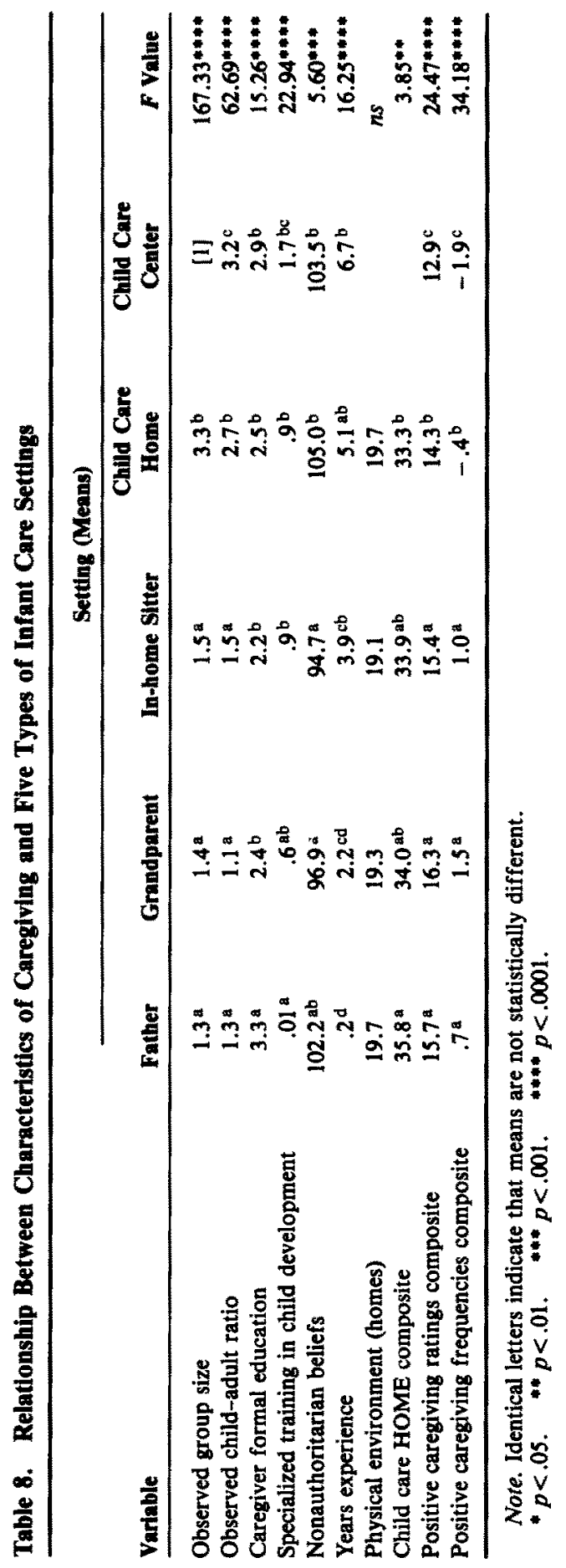


specialized training in child development, years of child care experience, and nonauthoritarian child-rearing beliefs. Paralleling the analyses for the whole sample, the backward elimination procedure was used only when the full regression models were significant.

As shown in Table 9, for father and grandparent care, higher ratings and frequencies of positive caregiving were associated with lower child-adult ratios and with more nonauthoritarian child-rearing beliefs. Because of the high correlation between child-adult ratio and group size in these settings ( $r=.99$ and $r=.87$ for fathers and grandparents, respectively), it is not surprising that only one of these variables was a significant predictor of positive caregiving. For in-home sitter care and child care homes these two variables were not as highly correlated, and positive caregiving was associated with smaller group sizes, lower child-adult ratios, nonauthoritarian child-rearing attitudes, and specialized training in child development (see Table 9). In center care smaller group sizes and more formal education were associated with more frequent positive caregiving behaviors. Thus, it appeared that structural and caregivers' characteristics were important within each type of care arrangement.

In the within-type analyses it also was possible to include measures of the physical environment (these could not be included in the overall analyses because different instruments were used for home- and for center-based care). The results of the regression analyses including the physical environment variable are presented in Table 10. In all three types of care, environments rated as safe, clean, and stimulating were associated with higher ratings of positive caregiving, and including the physical environment measure significantly improved the prediction of positive caregiving ratings.

\section{Other Factors Associated With Positive Caregiving Behaviors}

To examine the effects of different age groupings of children on observed caregiving, separate ANOVAs were conducted for home-based and for center care. For infants in centers, positive caregiving ratings and frequencies were contrasted for infants who were in classrooms consisting of infants only, infants and toddlers only, and mixed ages including preschoolers. ANOVAs were significant for frequency of positive caregiving behaviors, $F(2,100)=4.52, p<.01$. Tukey post hoc comparisons indicated that infants in classrooms with infants only $(M=-2.1, n=54)$ or infant and toddler combinations $(M=-2.4, n=25)$ received positive caregiving less frequently than did infants in mixed age groups $(M=-.9, n=24)$-despite the fact that the groups were the same size; $M s=8.3$ children in infant and toddler groups versus 7.7 children in mixed-age groups; $F(1,102)=2.2, n s$. No effect of age configuration was found for the composite rating of positive caregiving.

In home-based settings, the four possible configurations were the study infant alone, infants only, infants and toddlers, and mixed-age groups 


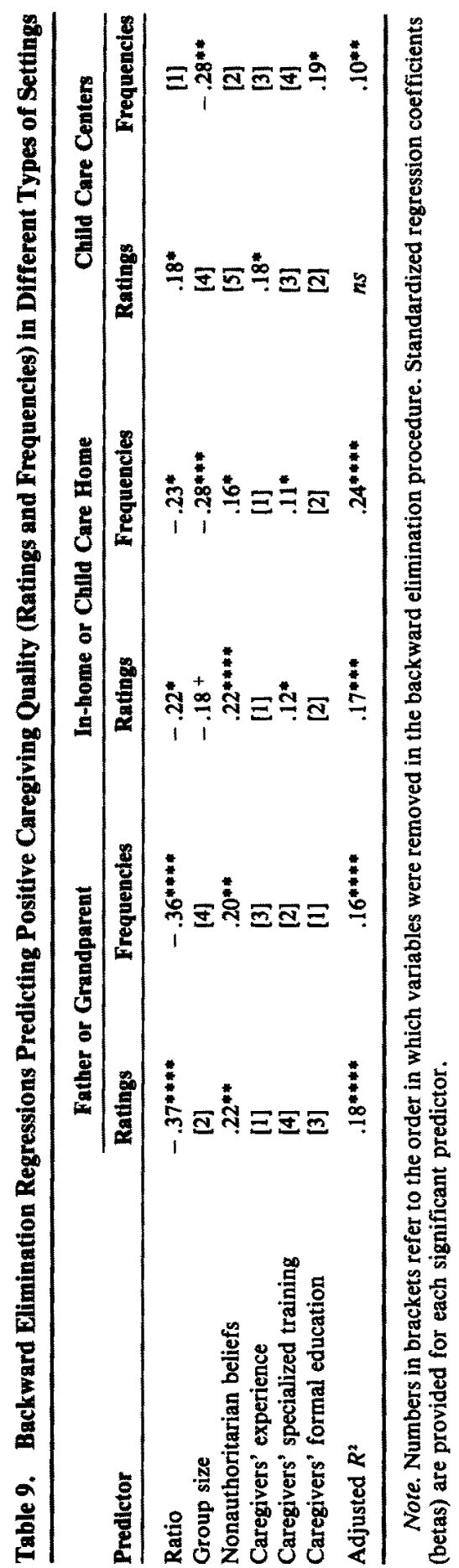




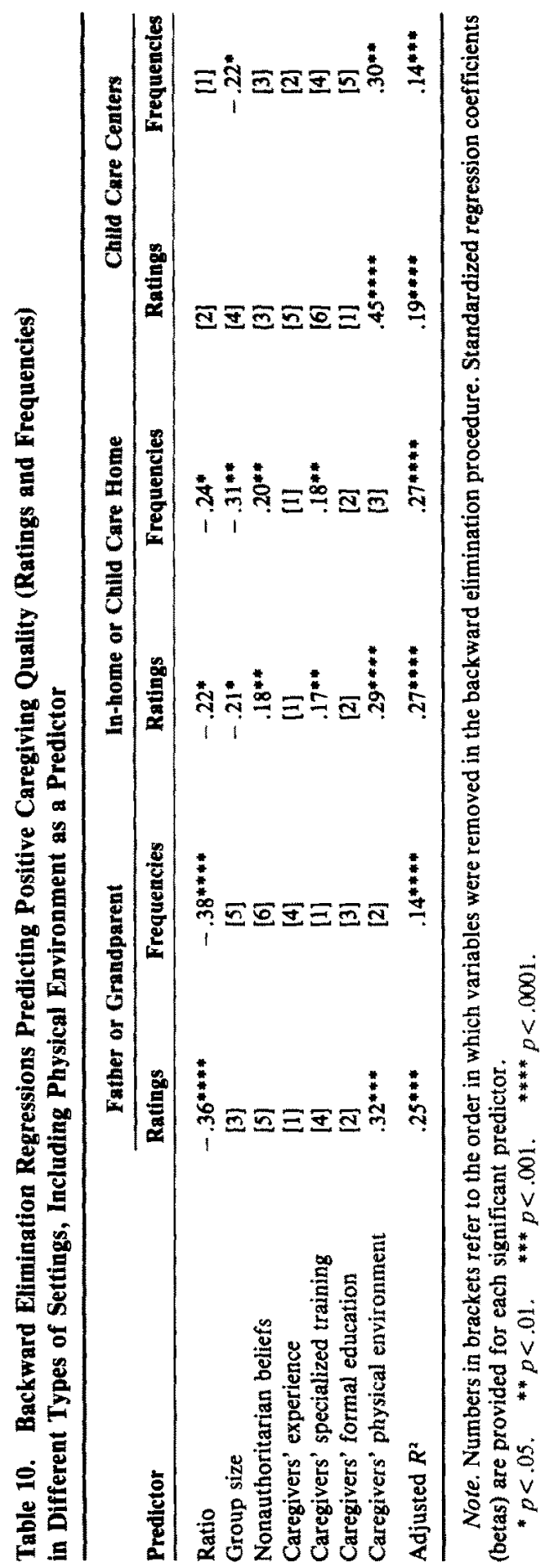


including preschoolers. Because of the small numbers of settings in which there were only infants or infants and toddlers $(n=13)$, it was not possible to include these groups in the analysis. Contrasting the positive caregiving ratings and frequencies for the study infant alone versus the study infant with any other children yielded highly significant $t$-test results: for positive caregiving ratings, $t(392)=8.31, p<.0001$; for positive caregiving frequencies, $t(410)=10.34, p<.0001$. Settings where the study infant was the only child in care had significantly more positive caregiving $(M s=16.2$ for ratings, 1.6 for frequencies) than did settings with other children $(M s=14.1$ for ratings, -.7 for frequencies). It did not make a difference whether the other children were the care provider's own or not.

Analyses to investigate differences in observed caregiving for infants in care part time (10-29 hr/week) versus full time ( $\geq 30 \mathrm{hr} /$ week) were conducted for center and home-based child care. Differences were not significant.

\section{DISCUSSION}

This investigation had three purposes. One was to identify the structural characteristics and caregivers' qualifications that are associated with the provision of sensitive, responsive, warm, and cognitively stimulating infant care. The second purpose was to contrast five different types of infant care in terms of structural features and caregivers' behaviors. The third purpose was to contrast the results of the current 10 -site collaborative project with other recent large-scale investigations of child care in the United States. We will discuss each of these issues in turn.

\section{Associations Between Structural \\ and Caregivers' Characteristics and Observed Caregiving}

Four factors were associated with infants receiving sensitive, warm, responsive care from their caregivers. Positive caregiving, assessed in terms of frequency counts and qualitative ratings, was higher when group sizes and child-adult ratios were smaller, when caregivers had nonauthoritarian beliefs about child rearing, and when the physical environments appeared safe, clean, and stimulating.

The importance of group size and ratios for infant care is consistent with research on toddler care (Allhusen, 1992; Clarke-Stewart et al., 1994; Fosburg, 1981; Fosburg et al., 1980; Howes, 1983; Ruopp et al., 1979; Stallings, 1980; Whitebook et al., 1990). In fact, it appears that infant child care is particularly susceptible to these structural dimensions. The closer the childadult ratio was to $1: 1$, the higher was the probability of sensitive, positive caregiving. To illustrate, when the child-adult ratio was $1: 1,38 \%$ of the caregivers were rated as of fering "highly sensitive" care; when the ratio was $2: 1,17 \%$ of the caregivers received a rating of "highly sensitive," and with a ratio of $4: 1$, only $8 \%$ of the caregivers were rated as "highly sensitive." 
The link between the number of children and positive caregiving was moderately strong in absolute terms $(r s=.36-.46)$; it was strong compared with associations with other structural and caregivers' dimensions and remained significant when these other dimensions were statistically controlled; and it was consistent across different types of care.

We suspect that the optimal number of children in a child care setting changes with children's development and that acceptable group sizes and ratios will prove to be higher for older children. Preschool-age children are expected to benefit (within limits) from learning to share the caregiver's attention and to work within small groups, to learn socially and cognitively from their interactions with peers. In this regard, it is notable that Galinsky et al. (1994) rated the overall quality of care for toddlers and preschoolers in home child care settings to be higher in homes with small groups of children than in settings with $1: 1$ ratios. Thus, the results of this investigation should be interpreted within the context of needs that may be developmentally specific to infancy.

Another factor associated with observed positive caregiving in this investigation was caregivers' beliefs about child rearing. Caregivers with nonauthoritarian child-rearing beliefs tended to have more positive interactions with infants than did caregivers with more authoritarian beliefs. These results are consistent with research by Arnett (1989) and McCartney (1984), which linked observed interactions with preschool-age children to caregivers' child-rearing beliefs. This association was not as strong as that between the number of children and positive caregiving, however.

Our finding of a significant association between positive caregiving behaviors and characteristics of the physical environment (safe, uncluttered, age-appropriate materials) was consistent with research on somewhat older children (Dunn, 1993; Howes, 1983; Scarr et al., 1994). It supports the lay views of parents and caregivers (Galinsky et al., 1994) about the inportance of the physical setting. This aspect of child care has generally been given less emphasis in the scientific community than other features such as child-adult ratios and caregivers' training. Our results suggest that the importance of the physical environment should not be underestimated.

In this investigation other factors were less clearly associated with observed positive caregiving for infants. The significant but small negative correlation between caregivers' experience and frequency of positive caregiving appeared to be the result of more experienced caregivers working in settings with more children (i.e., centers and child care homes). When group size, child-adult ratio, and caregivers' child-rearing beliefs were statistically controlled, experience, per se, did not affect positive caregiving. Caregivers' formal education and specialized training also did not appear to contribute substantially to the frequencies or ratings of positive caregiving, although research (McCartney, 1984; Vandell \& Powers, 1983; Whitebook et al., 
1994) indicates their importance with older children. Formal education and specialized training are expected to play larger roles with older children as caregivers use their training to of fer children educational activities and programs.

Taken together, the structural and caregivers' characteristics measured in this investigation accounted for only about one quarter of the variance in observed positive caregiving $\left(R^{2} s=.19, .27\right)$. This suggests that our conventional measures of regulable aspects of child care have a limited capacity to predict the quality of care an infant will receive. It is hoped that further research will uncover links with aspects of the child care situation as yet unrecognized as significant predictors of child care quality. For now, the evidence most clearly suggests that standards for infant care should include the number of children in the setting (child-adult ratio and group size) and the quality of the physical environment (safe, clean, and stimulating).

\section{Differences Associated With Types of Care}

Our second purpose was to examine variations associated with different types of care. Clear differences were documented. Group sizes and childadult ratios were significantly larger in child care centers than in child care homes, which were significantly larger than in father, grandparent, and inhome sitter care. Caregivers in centers had more specialized training and caregiving experience than did home-based providers. Along with these descriptive differences, there were differences in observed caregiving behaviors. Sensitive, positive, and involved care was most likely in in-home arrangements, with fathers, grandparents, and sitters, somewhat less likely in child care homes, and least likely in child care centers-although there were overlapping distributions across these types of care.

These results are quite consistent with other studies, in which toddlers in home-based care received more attention and affection than did toddlers in centers (Cochran, 1977; Golden et al., 1978; Hayes et al., 1983; Melhuish, Mooney, Martin, \& Lloyd, 1990). The most notable difference between our results and those of other researchers was that fathers and grandparents were observed to display more positive caregiving than unrelated providers in child care homes and centers. Although many parents believe that child care by family members is superior to care by nonrelatives, Galinsky et al. (1994) reported that care by relatives was less sensitive than care by unrelated home care providers. One possible explanation of this difference is that the relatives observed by Galinsky et al. cared for more children (1.6 vs. 1.3) and had less formal education than those observed in the current study $(46 \%$ vs. $14 \%$ with less than a high school diploma). In addition, it is possible that fathers and grandparents are more sensitive caregivers with infants, but not with older children. We will follow up this possibility in later analyses as the children in the NICHD study get older. It was not the case in this 
investigation that relatives per se provided better care than nonrelatives, because the care provided by unrelated sitters in the child's home was comparable to that of fathers and grandparents on our assessments of positive caregiving.

For infants, the structural variables of child-adult ratio and group size were consistently associated with positive caregiving behaviors within each type of care, as they were in the whole-sample analyses. In father and grandparent care, child-adult ratios, which were highly overlapping with group size, were associated with positive caregiving. In in-home sitter and child care home arrangements, both ratio and group size were associated with positive caregiving. In center-based care, group size predicted the frequency of positive caregiving. Consistently, then, across types of care, when more infants were being cared for, observed positive caregiving was lower.

Interestingly, differences in caregivers' beliefs, which contributed significantly to the caregiving behavior of home-based providers, did not predict observed caregiving in child care centers. This lack of association may be the result of the generally large ratios and group sizes in centers, which did not allow center caregivers the opportunity to implement their beliefs as they struggled to meet the demands of caring for several babies at one time. The challenge of caring for multiple infants was further demonstrated by the age configuration analyses. In centers, caregivers responsible for groups of infants or infants and toddlers showed less positive caregiving than did caregivers with mixed-age groups. Having several infants and toddlers all requiring care at the same time appears to result in caregivers having limited attention to devote to any single child. Older children's needs can often be met through verbal means, but infants require physical attention. Note though that the effect of caring for a large group of infants in a center was significant only for the frequency of positive caregiving; when the study infant did receive the caregiver's attention, it was not less sensitive or less positive.

\section{Quality of Infant Child Care}

Our third purpose was to provide a window into infant child care in the United States. Previous large-scale studies (e.g., Galinsky et al., 1994; Helburn et al., 1995; Whitebook et al., 1990) focused on older children and on selected child care settings (centers only, family day care only). In the NICHD study, families were recruited at the children's birth, and extensive observations were conducted in a range of settings when the infants were 6 months old. The majority of infants $(70 \%-80 \%)$ observed in the NICHD study were judged to be receiving care that was moderately or highly sensitive, moderately or highly positive. Some caution should be taken in generalizing these figures to the quality of infant care in the United States. The study was not designed to be nationally representative, and our sampling 
plan excluded adolescent mothers, very ill newborns, and mothers who did not speak English. Infants in these families may have less access to highquality child care than the infants of participating families. In addition, $15 \%$ of the providers who were contacted refused to participate in the study; and care in those settings may well have lowered the overall ratings. ${ }^{5}$ (It should be noted that the refusal rate in other large-scale child care studies has been substantially higher, however, about $45 \%$.) Within these constraints, observations obtained in this investigation suggest that the quality of nonmaternal infant care is not as poor as might be surmised from other investigations such as the Cost, Quality, and Child Outcomes Study (Helburn et al., 1995), the Child Care Staffing Study (Whitebook et al., 1990), and the Study of Children in Family Child Care and Relative Care (Galinsky et al., 1994), which all reported high proportions $(25 \%-40 \%)$ of inadequate care and low proportions $(8 \%-12 \%)$ of "good" care.

Many factors may have contributed to the discrepant findings. One possibility is that other studies simply used different measures to assess child care. Although the NICHD study and the other investigations assessed similar aspects of child care settings (such as caregiver sensitivity, presence of stimulating activities, and physical safety), different instruments were used, and comparisons across these instruments may not be valid. For example, what is labeled good in one study may be different from what is defined as good in another study. There is some evidence of such measurement differences. As a site-specific substudy at one of the 10 sites in the NICHD study, the same measure used by Galinsky et al. (the Family Day Care Rating Scale, Harms \& Clifford, 1989) was administered in 30 child care homes. Although scores on this measure were highly correlated with the ORCE positive caregiving rating $(r=.71)$, the labels attached to these ratings were different. What was called moderately sensitive and highly sensitive on the ORCE qualitative rating was equivalent to what was called mediocre on the Harms and Clifford scale. Thus, the labeling of glasses-

${ }^{3}$ This was a problem, particularly for rating the quality of care in child care homes. Child care home providers were disproportionately likely to refuse to have an observer come into their homes $(27 \%$ of the child care home providers contacted refused to allow an observer access). Based on information gathered from the care provider or the mother over the phone, there was no significant difference in the number of children in these child care homes, but the unobserved homes had higher child-adult ratios $(3.6: 1$ vs. $2.7: 1, F(1,262)=19.6, p<.0001)$, and the care providers had less education $(68 \%$ vs. $52 \%$ had no more than a high school education; $\chi^{2}(5)=15.8, p<.01$ ). As a result of these differences, our estimates of positive caregiving frequencies and ratings in child care homes may be biased upwards. Similar differences between observed and unobserved care were found for in-home care providers (group size: 2.2 vs. 1.6, $F(1,294)-8.3, p<.01$; child-adult ratio: 2.0 vs. $1.3, F(1,300)=25.7, p<.0001$; education: $70 \%$ vs. $47 \%$ with no more than high school, $\left.x^{2}(5)=16.1, p .01\right)$, but the problem was not as significant because the refusal rate for these caregivers was only $14 \%$. For child care centers, the refusal rate was only $3 \%$. 
or classes-as half full or half empty may have contributed to the apparent discrepancy between observations in this investigation and observations in other studies.

The importance of the measurement differences is underscored further by how researchers handled rounding. In the Cost, Quality, and Child Outcomes Study, for example, rounding up scores above .5 to the next higher scale point instead of rounding them down would have doubled the proportions of care labeled good. Instead of finding $40 \%$ poor, $51 \%$ mediocre, and $8 \%$ good, the proportions would have been $20 \%$ poor, $64 \%$ mediocre, and $16 \%$ good. Thus, it appears that different conclusions about child care quality are, at least partially, the result of measurement differences.

We do not believe, however, that discrepancies are solely the result of these measurement differences, because the child care settings also differed on objective, structural characteristics. In the NICHD study the average child-adult ratio in centers was 3.2:1, whereas in the Cost and Quality study the ratio for infants and toddlers was 3.6:1, and in the Staffing study the ratio was 3.9:1. In the NICHD study $71 \%$ of centers met the 3:1 ratio recommended by the American Public Health Association and the American Academy of Pediatrics (1992); in the Staffing study, only $36 \%$ did. In the child care homes observed in the NICHD study, the average child-adult ratio was 2.7:1, whereas in the Study of Family and Relative Care, the average ratio was 3.3:1. These structural differences suggest that the NICHD study observed care in settings that had greater potential for positive caregiving.

These structural differences (and differences in observed caregiving) may partially reflect the locations in which the observations were conducted. The other large-scale studies were conducted in states such as North Carolina, Texas, and Colorado, which have minimal child care standards. Although several states in the NICHD sample overlap with those in the other investigations (California, North Carolina, and Virginia), and still other states included in the NICHD study have relatively low standards (e.g., Arkansas), the NICHD study also included states with relatively high child care standards (e.g., Washington, Kansas, and Massachusetts). The structural characteristics and observed caregiving in these states may have contributed to the overall scores that were obtained. In later analyses, it is our intention to explore further the links between state standards and observed caregiving. Within these analyses, we will examine variations in child care across the 10 sites.

Another important difference between the NICHD study and the other large-scale studies was the inclusion of a broader range of care arrangements -that is, care by fathers, grandparents, and in-home sitters, and care that was part time as well as full time. Almost half of the infants in the NICHD study were in such informal care arrangements. Past inquiries have not investigated the care provided by fathers, grandparents, and in-home sitters in 
any detail. The quality of observed care in our study was, in fact, significantly higher in these arrangements than in child care homes and child care centers -the settings observed most frequently in prior studies. The inclusion of these additional types of care, then, increased the proportions of care judged to be somewhat or highly sensitive, stimulating, and positive. Whether father, grandparent, and in-home sitter care continues to be associated with positive caregiving is a question that will be examined when the study children are toddlers and preschoolers. Observing part-time as well as fulltime care arrangements did not appear to affect our findings substantially, as no differences in positive caregiving were found between part-time and full-time care.

There are two important issues that were not examined in this article. The first pertains to the determination of which children are placed in different child care arrangements. It was simply beyond the scope here, where the focus was on relations between different aspects of infant child care experiences, to describe the demographic and psychological characteristics of families that might be associated with different quality and types of child care. Such topics are to be explored in considerable detail in another article being prepared by study investigators. A second critical issue pertains to the effects of the infant child care measures on children's subsequent social and intellectual development. To this end, children's social and cognitive development was assessed at 15, 24, and 36 months. When these assessments are coded and analyzed, we will seek to determine if the variations in infant child care reported here contribute to differences in child adjustment.

This report, then, represents one step in a larger research endeavor examining the contributions of early child care and family experiences to children's development. The focus is on child care during the 1st year, observed in a wide range of arrangements including care by fathers, grandparents, and inhome sitters, as well as child care homes and child care centers. The analysis adds to our knowledge in a number of ways, but perhaps most significantly by suggesting that much of the informal care being provided for young infants is of reasonably high quality, particularly if the infant is the only young child in the care arrangement. Whether variation in quality of care observed at 6 months predicts infants' subsequent development will be answered in future reports involving the longitudinal follow-up of this sample.

\section{REFERENCES}

Abbott-Shim, M., \& Sibley, A. (1987). Assessment Profile for Early Childhood Programs. Atlanta, GA: Quality Assist.

Allhusen, V.D. (1992). Differences in day care experiences of infants in three different teacherchild ratio groups: Variations in caregiving quality. Unpublished doctoral dissertation, Cornell University, Ithaca, NY. 
American Public Health Association \& American Academy of Pediatrics. (1992). Caring for our children: National health and performance standards: Guidelines for out-of-home child care programs. Ann Arbor, MI: Author.

Arnett, J. (1989). Caregivers in day-care centers: Does training matter? Journal of Applied Developmental Psychology, 10, 541-552.

Berk, L. (1985). Relationship of educational attainment, child oriented attitude, job satisfaction, and career commitment to caregiver behavior toward children. Child Care Quarterly, 14, 103-129.

Bollen, K.A. (1989). Structural equations with tatent variables. New York: Wiley.

Bradley, R.H. (1995). Home environment and children's development: Age and demographic differences. Paper presented at the fifth annual conference of the Center for Human Development and Developmental Disabilities: Family Relations and the Development of Competence. New Brunswick, NJ.

Bradley, R.H., \& Caldwell, B.M. (1976). The relation of infants' home environments to mental test performance at 54-months. A follow-up study. Child Development, 47, 1172-1174.

Burchinal, M.R., Roberts, J.E., Nabors, L.A., \& Bryant, D.M. (1996). Quality of center child care and infant cognitive and language development. Child Development, 67, 606-620.

Cadden, V. (1994, March). The state of the states: Experts rate child care across the country. Working Mother, 32-38.

Caldwell, B.M., \& Bradley, R.H. (1984). Home observation for measurement of the environment. Little Kock: University of Arkansas at Little Kock.

Carnegie Corporation of New York (1994). Starting points: Meeting the needs of our youngest children. New York: Author.

Clarke-Stewart, K.A., Gruber, C.P., \& Fitzgerald, L.M. (1994). Children at home and in day care. Hillsdale, NJ: Erlbaum.

Cochran, M.M. (1977). A comparison of group day and family child-rearing patterns in Sweden. Child Development, 48, 702-707.

Cox, M., Owen, M., \& Lewis, J.M. (1989, April). Prenatal marital relationships and child development at age $21 / 2$. Paper presented at the biennial meeting of the Society for Research in Child Development, Kansas City.

Crockenberg, S., \& Covey, S.L. (1991). Marital conflict and externalizing behaviors in children. In D. Cicchetti \& S.L. Toth (Eds.), Rochester Symposium on Developmental Psychology: Vol. 3. Models and integrations (pp. 235-260). Rochester, NY: University of Rochester Press.

Dunn, L. (1993). Proximal and distal features of day care quality and children's development. Early Childhood Research Quarterly, 8, 167-192.

Easterbrooks, M.A., \& Goldberg, W.A. (1984). Toddler development in the family: Impact of father involvement and parenting characteristics. Child Development, 55, 740-752.

Fosburg, S. (1981). Family day care in the United States: National Day Care Home Study: Vol. 1. Summary of findings (DHHS Publication No. OHDS 80-30282). Washington, DC: U.S. Department of Health and Human Services.

Fosburg, S., Hawkins, P.D., Singer, J.D., Goodson, B.D., Smith, J.M., \& Brush, L.R. (1980). National Day Care Home Study. Cambridge, MA: Abt.

Galinsky, E., Howes, C., Kontos, S., \& Shinn, M. (1994). The study of children in family child care and relative care: Highlights of findings. New York: Families and Work Institute.

Goelman, H. (1988). The relationship between structure and process variables in home and day care settings on children's language development. In A.R. Pence (Ed.), Ecological research with children and families: From concepts to methodology (pp. 16-34). New York: Teachers College Press.

Golden, M., Rosenbluth L., Grossi, M.T., Policare, H.J., Freeman, H., \& Brownlee, E.M. (1978). The New York City Infant Day Care Study. New York: Medical and Health Research Association of New York City. 
Harms, T., \& Clifford, R.M. (1980). Early Childhood Environment Rating Scale. New York: Teachers College Press.

Harms, T., Clifford, R.M. (1989). Family Day Care Rating Scale. New York: Teachers College Press.

Hayes, W.A., Massey, G.C., Thomas, E. A. C., David J., Milbrath, C., Buchanan, A., \& Lieberman, A. (1983). Analytical and technical report of the National Infant Care Study. San Mateo, CA: Urban Institute for Human Services.

Helburn, S., Culkin, M.L., Morris, J., Mocan, N., Howes, C., Phillipsen, L., Bryant, D., Clifford, R., Cryer, D., Peisner-Feinberg, E., Burchinal, M., Kagan, S.L., \& Rustici, J. (1995). Cost, quality, and child outcomes in child care centers. Executive summary. Denver: University of Colorado, Department of Economics.

Hofferth, S.L., Brayfield, A., Deich, S., \& Holcomb, P. (1991). National child care survey 1990. Washington, DC: Urban Institute.

Howes, C. (1983). Caregiver behavior in centers and family day care. Journal of Applied Developmental Psychology, 4, 99-107.

Kagan, S.L., \& Newton, J.W. (1989). For-profit and nonprofit child care: Similarities and differences. Young Children, 45, 4-10.

Kisker, E.E., Hofferth, S.L., Phillips, D.A., \& Farquhar, E. (1991). A profile of child care settings: Early education and care in 1990 (Final report for U.S. Department of Education, No. LC88090001). Princeton, NJ: Mathematica.

Kontos, S. (1994). The ecology of family day care. Early Childhood Research Quarterly, 9, 87-110.

Kontos, S, \& Fiene, R. (1987). Child care quality, compliance with regulations, and children's development: The Pennsylvania Study. In D.A. Phillips (Ed.), Quality in child care: What does research tell us? (pp. 57-80). Washington, DC: National Association for the Education of Young Children.

Logue, M.E., Eheart, B.K., \& Steinkamp, M.W. (1989, March). Child age and teacher training: Their relationship to day care teachers' behaviors, expectations, and goals. Paper presented at the biennial meeting of the Society for Research in Child Development.

McCartney, K. (1984). The effect of quality of day care environment upon children's language development. Developmental Psychology, 20, 244-260.

Melhuish, E.C., Mooney, A., Martin, S., \& Lloyd, E. (1990). Type of childcare at 18 months1. Differences in interactional experience. Journal of Child Psychology and Psychiatry, $31,849-859$.

NICHD Early Child Care Research Network. (1992). The National Institute of Child Health and Human Development (NICHD) Study of Early Child Care: Recruitment procedures (Chapter 4). Operations manual.

NICHD Early Child Care Research Network. (1995). Sampling plan and subject recruitment. Poster presented at the biennial meeting of the Society for Research in Child Development, Indianapolis, Indiana.

NICHD Early Child Care Research Network. (1996). Familial factors associated with infant child care characteristics. Manuscript submitted for publication.

Phillips, D.A., Scarr, S., \& McCartney, K. (1987). Dimensions and effects of child care quality: The Bermuda Study. In D.A. Phillips (Ed.), Quality in child care: What does research tell us? (pp. 43-56). Washington, DC: National Association for the Education of Young Children.

Ruopp, R., Travers, J., Glantz, F., \& Coelen, C. (1979). Children at the center. Cambridge, MA: Abt.

Scarr, S. (1984). Mother care/other care. New York: Basic Books.

Scarr, S., Eisenberg, M., Deater-Deckard, K. (1994). Measurement of quality in child care centers. Early Childhood Research Quarterly, 9, 131-151.

Schaefer, E.S., \& Edgerton, M. (1985). Parcnt and child correlates of parental modernity. 
In I.E. Sigel (Ed.), Parental belief systems (pp. 287-318). Hillsdale, NJ: Erlbaum.

Stallings, J.A. (1980). An observation study of family day care. In J.C. Colberg (Ed.), Home day care: A perspective (pp. 25-47). Chicago: Roosevelt University.

Stith, S.M., \& Davis, A.J. (1984). Employed mothers and family day-care substitute caregivers: A comparative analysis of infant care. Child Development, 55, 1340-1348.

Vandell, D.L., \& Powers, C.P. (1983). Day care quality and children's free play activities. American Journal of Orthopsychiatry, 53, 493-500.

Wachs, T.D. (1991). Environmental considerations in studies with nonextreme groups. In T.D. Wachs \& R. Plomin (Eds.), Conceptualization and measurement of organismenvironment interaction (pp. 44-67). Washington, DC: American Psychological Association.

Whitebook, M., Howes, C., \& Phillips, D. (1990). Who cares? Child care teachers and the quality of care in America (Final report). National Child Care Staffing Study. Oakland, CA: Child Care Employee Project.

Winer, B.J. (1971). Statistical principles in experimental design. New York: McGraw-Hill. 